\title{
Role of Hedgehog signaling pathway in proliferation and invasiveness of hepatocellular carcinoma cells
}

\author{
WEI-TING CHENG $^{1 *}$, KAI XU ${ }^{2 *}$, DE-YING TIAN ${ }^{1}$, ZHENG-GANG ZHANG $^{1}$, LI-JIANG LIU ${ }^{3}$ and YING CHEN $^{3}$ \\ Departments of ${ }^{1}$ Infectious Diseases and ${ }^{2}$ Orthopaedics, Tongji Hospital, Tongji Medical College, \\ Huazhong University of Science and Technology, Wuhan 430030; ${ }^{3}$ Department of Pathology, \\ School of Medicine, Jianghan University, Wuhan 430056, P.R. China
}

Received October 20,2008; Accepted December 2, 2008

DOI: 10.3892/ijo_00000209

\begin{abstract}
The Hedgehog (Hh) pathway has been confirmed a contributor to the carcinogenesis and progression of various tumor types. To investigate the Hh signaling activity in human hepatocellular carcinoma (HCC), we detected the expression levels of Hh pathway components (Shh, Ptch1 and Gli2) in 57 samples of HCC and corresponding adjacent-tumor liver tissues. The Hh pathway was overexpressed in cancer tissues compared with non-cancer tissues and correlated closely with histologic differentiation and portal venous invasion of HCC. To elucidate the relationship between $\mathrm{Hh}$ signaling and HCC progression, we performed a further study in vitro. First, the expression levels of the signaling were detected in a subset of hepatoma cell lines and SMMC-7721 cells selected with high level of Hh signaling expression. Next, we employed KAAD-cyclopamine (a specific inhibitor of Hedgehog pathway) to block the $\mathrm{Hh}$ pathway in SMMC-7721 cells and assessed the changes of their biological behaviors. The results showed that the blockade of Hh signaling pathway by KAAD-cyclopamine induced reduction of DNA synthesis leading to marked cell growth inhibition and also caused significant attenuation in invasiveness and motility of $\mathrm{HCC}$ cells. Collectively, our data demonstrated that the Hh pathway plays an important role in HCC development and invasion. Blockade of the Hh signaling pathway may be a potential target of new therapeutic strategy for HCC.
\end{abstract}

\section{Introduction}

Hepatocellular carcinoma (HCC) is the fifth most malignant neoplasm in the world, with approximately 1 million new cases

Correspondence to: Professor De-Ying Tian, Department of Infectious Disease, Tongji Hospital, Tongji Medical College, Huazhong Universty of Science and Technology, 1095 Jie Fang Da Dao, Wuhan 430030, P.R. China

E-mail: dytian@tjh.tjmu.edu.cn

${ }^{*}$ Contributed equally

Key words: carcinoma, hepatocellular, proliferation, invasiveness, Hedgehog, cyclopamine per year worldwide and causes proximately 100,000 deaths annually in China $(1,2)$. The etiology of HCC includes chronic viral hepatitis, alcohol abuse, environmental carcinogens or genetic disorders; hepatitis B virus (HBV) infection is the major cause of HCC in China. Although several risk factors for HCC development are known, therapeutic options for the disease are very limited. The hepatic resection remains the most effective treatment (3), but the prognosis of HCC is generally poor, with high postoperative recurrence and invasiveness of primary tumor responses (4). Decades of intense research efforts have aimed at better understanding the underlying etiologic and pathophysiological mechanisms, but its molecular mechanisms remain unclear. Therefore, it is vital to explore new molecular markers for treatment strategies have the potential to significantly improve the prognosis of this dismal disease.

The hedgehog $(\mathrm{Hh})$ signaling pathway is a highly conserved system, which plays a crucial role in tissue patterning, cell differentiation and proliferation (5). In vertebrate organisms, the signaling pathway is initiated by the binding of ligands (sonic, Indian, and desert hedgehog) to the membranous receptor patched (Ptch) which in turn alleviates the suppression on smoothened (Smo), a 7-transmembranous domains protein receptor, subsequently Smo triggers a series of intra-cellular events with resultant activation of the zincfinger transcription effectors, glioma-associated oncogenes (Gli1, Gli2, Gli3) transcription factor, which induces the expression of numerous target genes that regulate proliferation, differentiation, and extracellular matrix interactions (5-7). Apart from epidermis, myoblasts, and neural stem cells and during tissue repair, Hh signaling pathway remains inactive in most normal mature tissues including adult liver, despite the pathway being critical in the early development of the liver and contributing to differentiation between hepatic and pancreatic tissue formation (8-12).

Aberrant activation of the Hh signaling pathway, especially ectopic expression of Gli2 is responsible for the onset and progression of tumorigenesis, in cancers such as of the pancreas, colon, stomach, lung, prostate, breast and skin (13-21). Downregulation of Gli2 or inhibition of the pathway with a ligand-blocking antibody or KAAD-cyclopamine, the selective Smo antagonist, has been shown to retard the growth of tumors and to decrease tumor size. However, the role of the 
pathway in pathogenesis of HCC is still indistinct in spite of a few previous studies (22-24), particularly concerning invasiveness there is lack of information. In the current study, expression of the Hh signaling pathway in HCC was detected and the relationship with regard to clinicopathologic characteristics was investigated. In addition, the activation of $\mathrm{Hh}$ signaling in a subset of liver cell lines was evaluated. Finally, the response of HCC cells to inhibition of the $\mathrm{Hh}$ signaling by KAAD-cyclopamine was assessed by evaluating cell proliferation, motility and invasiveness.

\section{Patients and methods}

Patients and specimens. A total of 57 HCC patients who had undergone liver resection without preoperative treatment at Tongji Hospital of Tongji Medical College of Huazhong University of Science and Technology between June 2004 and December 2007 were examined. All tumor specimens were pathologically diagnosed as HCC. The age of patients ranged from 24 to 70 years, with an average age of 46.4 years, and there were 43 males and 14 females. The number of patients positive for $\mathrm{HBV}$ and $\mathrm{HCV}$ was 47 and 3 respectively. There were 27 well-, 16 moderately- and 14 poorly-differentiated HCC. Portal vein tumor thrombus was observed in 26 patients.

Immunohistochemistry. Immunohistochemical stains were performed on formalin-fixed and paraffin-embedded tissue sections $(4 \mu \mathrm{m})$. The sections were prepared according to classical methods and treated with blocking solution before being sequentially incubated with primary $\mathrm{Ab}$ against Shh (1:100, Santa Cruz, USA), Ptch1 (1:100, Santa Cruz, USA), Gli2 (1:200, Abcam, UK) overnight at $4^{\circ} \mathrm{C}$, followed by biotinylated $\mathrm{Ab}$ and $\mathrm{HRP}$-conjugated streptavidin (each for $30 \mathrm{~min}$ at room temperature). Detection was achieved with diaminobenzidine and hematoxylin counter staining. No significant staining was observed in the negative controls, which were treated with the same species normal IgG in place of primary $\mathrm{Ab}$. The expression was evaluated independently by two pathologists; at least twice for each tissue sample with similar results.

Cell culture. Cell lines Hep3B and Huh-7 were obtained from the Chinese Type Culture Collection (Wuhan), L02, HepG2, and SMMC-7721 were generously provided by Drs Liming Xia and Wei Yan. All cell lines were grown in Dulbecco's modified essential medium (DMEM, Thermo, USA) supplemented with $10 \%$ fetal bovine serum (FBS, Invitrogen, USA). The cells were grown at $37^{\circ} \mathrm{C}, 5 \% \mathrm{CO}_{2}$ in fully humidified air. Cells were treated with KAAD-cyclopamine (Toronto Research Chemicals, Canada), the special antagonist of smoothened (Smo), control medium containing tomatidine (Sigma, USA), the structurally similar compound with nonspecific inhibition on hedgehog signaling, or DMSO alone.

RNA extraction and RT-PCR. Total RNA was extracted from all cell lines and typical tissue samples using TRIzol reagent (Invitrogen), and lysates were treated with DNA-free DNase treatment and removal reagents (Ambion, USA). The housekeeping gene GAPDH was used as a loading control. RT-PCR was performed using ThermoScript RT-PCR system (Invitrogen). In brief, $1 \mu \mathrm{g}$ of total RNA was used in a $20 \mu \mathrm{l}$ reverse transcription assay. Subsequently, $2 \mu 1$ of the reverse transcription product was used in a $25 \mu 1 \mathrm{PCR}$ reaction. All $\mathrm{PCR}$ reactions were performed at $5-55^{\circ} \mathrm{C}$ annealing temperature for 25-32 cycles. All primers used in this study are listed in Table I.

MTT assay. The antiproliferative effects of KAAD-cyclopamine with different concentration on hepatoma cells were detected by the methyl thiazolyl tetrazolium (MTT) assay. The cells were cultured in 96 -well plates at $2 \times 10^{5}$ cells per well and treated with $10 \%$ FBS medium containing KAADcyclopamine at various concentrations $(1,5,10 \mu \mathrm{M})$ for 12 , 24, 48, 60, $72 \mathrm{~h}$. All experiments were repeated three times. $20 \mathrm{ml}$ MTT $(10 \mathrm{~g} / \mathrm{l})$ was added to each well, medium was discarded after $4 \mathrm{~h}$, followed by the addition of $150 \mathrm{ml}$ DMSO. The $490 \mathrm{~nm}$ absorbance was measured by a Bio-Tek microplate reader, the inhibitory ratios (IR) were calculated as follows: IR $(\%)=[(1$-absorbance of the treated wells $) /[$ absorbance of the control wells)] x 100.

BrdU incorporation assay. To measure DNA synthesis rates, following treatments for $72 \mathrm{~h}$, the cells were chased by 10 $\mu \mathrm{mol} / \mathrm{l}$ 5-bromodeoxyuridine (BrdU,) for $2 \mathrm{~h}$. BrdU was detected with mouse anti-BrdU (1:200, Santa Cruz, USA) for $2 \mathrm{~h}$ followed by fluorescein isothiocyanate-conjugated antibody incubated for $45 \mathrm{~min}$, protected from direct light. Total DNA was stained with PI. BrdU incorporation into DNA and DNA content in nuclei were detected and quantified on a FACScan (BD, USA). Shown here are the representative data seen in three independent experiments. Note that: \% cells in active DNA synthesis is defined as $\mathrm{BrdU}^{+}$cells/total cells (the events in $\mathrm{R} 2$ area/total events) and the average BrdU incorporation into DNA (mean BrdU signal intensities in R2 events) is shown.

Wound healing assay. Confluent cell monolayers in 24-well plates were scrape-wounded using a micropipette tip. After being washed, cells were cultured in media with $0.5 \%$ FCS. Migration rate (average velocity) and degree of wound closure were assessed by measuring the distance between wound edges at time intervals of $3 \mathrm{~h}$, representative wells were observed by inverted microscope. The cell movement velocity was determined by tracing single cells at different time-points, using MetaMorph software (Metamorph Imaging System, USA). All samples were tested in triplicate and were scored in a double-blinded manner by three investigators.

Time-lapse video. For time-lapse observation of cell movement, the cells plated in complete medium were monitored by inverted microscope with a charge coupled-device camera at planned intervals. Phase-contrast images were captured and analyzed with Metamorph software (Metamorph Imaging System). The motility of individual cells was evaluated by tracking their movement from images recorded every $10 \mathrm{~min}$. The average speed $(\mu \mathrm{m} / \mathrm{h})$ of locomotion was calculated as the total track length divided by the number of hours recorded. For each experimental condition, 30-50 cells were analyzed. 
Table I. Sequence for RT-PCR primers.

\begin{tabular}{ll}
\hline Shh & 5'-GATGTCTGCTGCTAGTCCTCG-3' \\
& 5'-CACCTCTGAGTCATCAGCCTG-3' \\
Ihh & 5'-CGGACGCTATGAAGGCAAGA-3' \\
& 5'-TGAAGATGATGTCTGGATTGTAATTG-3' \\
Smo & 5'-GTTCTCCATCAAGAGCAACCAC-3' \\
& 5'-CGATTCTTGATCTCACAGTCAGG-3' \\
Ptch1 & 5'-CAGAGAAGGCTTGTGGCCAC-3' \\
& 5'-GCTCAATGACTTCCACCTTCG-3' \\
Gli1 & 5'-CTCCCGAAGGACAGGTATGTAAC-3' \\
& 5'-CCCTACTCTTTAGGCACTAGAGTTG-3' \\
Gli2 & 5'-TGGCCGCTTCAGATGACAGATGTTG-3' \\
& 5'-CGTTAGCCGAATGTCAGCCGTGAAG-3' \\
Gli3 & 5'-GGCCATCCACATGGAATATC-3' \\
& 5'-TGAAGAGCTGCTACGGGAAT-3' \\
GAPDH & 5'-ATCTTCCAGGAGCGAGATCCC-3' \\
& 5'-CGTTCGGCTCAGGGATGACCT-3' \\
\hline
\end{tabular}

Modified Boyden chamber invasion assays. The effect of KAAD-cyclopamine on hepatocellular carcinoma was determined using modified Boyden chamber assays as previously described (25). Briefly, 24-well transwell units with polycarbonate membrane filters $(6.5 \mathrm{~mm}$ diameter, $8 \mu \mathrm{m}$ pore size, Costar, Corning, USA) were coated with Matrigel $\left(100 \mu \mathrm{g} / \mathrm{cm}^{2} / 100 \mu \mathrm{l}\right.$ PBS). Cells $\left(1 \times 10^{5} / 200 \mu 1\right.$ DMEM with $0.5 \%$ FBS ) were added to the upper compartment and incubated for $48 \mathrm{~h}$ in the absence or presence of KAADcyclopamine $(10 \mu \mathrm{mol} / \mathrm{l})$ at $37^{\circ} \mathrm{C}$. The lower chambers were filled with $2 \mathrm{ml}$ DMEM supplemented with 5\% FBS as chemoattractant. After removal of nonmigratory cells from the upper surface of the filter, invasive cells that had passed through to the lower surface of the filter were fixed and stained with crystal violet. Invasive cells were scored by counting at least five fields per filter. Counting accuracy was controlled by optical density OD570 quantification of methanol-solubilized dye.

Statistical analyses. Associations between gene expression and clinicopathologic variables were analyzed by Fisher's exact test. The variables such as the data using cell lines were compared by Mann-Whitney's U test, One- or Two-way ANOVA according to the experimental design applied. All statistical analyses were performed using the SPSS 11.0 software program (SPSS, USA). A two-tailed $\mathrm{P}<0.05$ was considered statistically significant.

\section{Results}

Overexpression of Hh pathway in HCC comparing with its corresponding adjacent-tumor liver tissue. We detected Shh, Ptch1 and Gli2 expressions in 57 cases of $\mathrm{HCC}$ and the
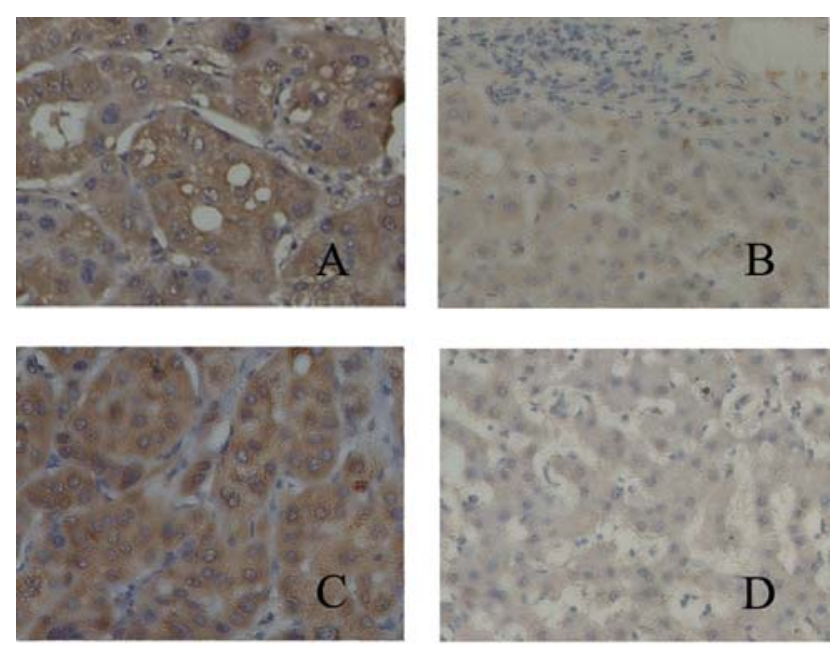

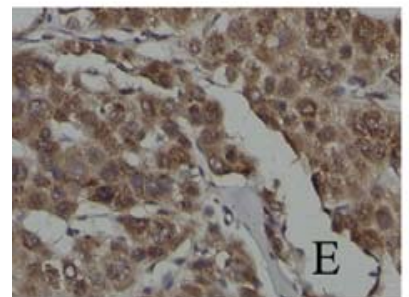

Tumor

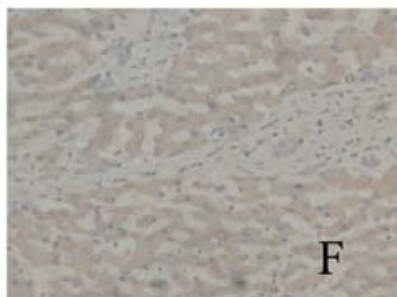

Non-tumor
Figure 1. Result of immunostaining for Shh (A and B), Ptch1 (C and D), and Gli2 (E and F) in HCC tissues and corresponding adjacent-tumor liver tissues (x200). The expressions of Shh and Ptch1 were focally observed in the cytoplasm of the parenchymal cells, and Gli2 expressed in cytoplasm and nucleus with predominance in the cytoplasm. The overexpression of the three molecules in carcinoma presented a striking contrast to non-tumor liver tissues.

corresponding tumor-adjacent liver tissues for the purpose of evaluating the hedgehog signaling pathway activation. By immunohistochemical staining, Shh and Ptch1 expressions were defined as cytoplasmic staining with either stippled or granular pattern, and Gli2 located in cytoplasm and/or nucleus, with predomination in cytoplasm (Fig. 1). As shown in Table II, there was a significantly difference in expression of Shh and Ptch1 between HCC tissues and the corresponding tumor-adjacent liver tissues $(63.2 \%$ vs. $43.9 \%$ and $52.6 \%$ vs. $28.1 \%$ respectively) $(\mathrm{P}<0.05)$. In addition, positive expression of Gli2 was remarkably stronger in HCC (70.2\%) than non-tumor liver tissues $(42.1 \%)(\mathrm{P}<0.01)$.

Relationship between immunohistochemical results and clinicopathologic features. Table II shows the expression distinction of the Hh components in HCC varied clinicopathologic factor groups. Overexpression of three components, Shh, Ptch1 and Gli2, was significantly associated with portal venous invasion $(\mathrm{P}<0.05)$; meanwhile, Shh and Gli2 were notably correlated to HCC histologic differentiation $(\mathrm{P}<0.05)$. But the results did not demonstrate any association between the Hh pathway and gender, tumor size and virus infection.

Different expressions of Hh pathway components in HCC cell lines. Five cell lines including L02, HepG2, Hep3B, SMMC-7721 and Huh7 as well as representative HCC tissue and adjacent-tumor tissue were investigated for expression 
Table II. Expression of Hh signaling in HCC and adjacent-tumor liver tissues, n (\%).

\begin{tabular}{|c|c|c|c|c|c|c|}
\hline & Shh pos & P-value & Ptch1 pos & $\mathrm{P}$-value & Gli2 pos & P-value \\
\hline Hepatocellular carcinoma & $36(63.2)$ & & $30(52.6)$ & & $40(70.2)$ & \\
\hline Adjacent-tumor liver tissues & $25(43.9)$ & $0.039^{\mathrm{a}}$ & $16(28.1)$ & $0.013^{\mathrm{a}}$ & $24(42.1)$ & $0.002^{\mathrm{b}}$ \\
\hline \multicolumn{7}{|l|}{ Sex } \\
\hline Male & $26(60.5)$ & & $24(55.8)$ & & $30(69.8)$ & \\
\hline Female & $10(71.4)$ & 0.46 & $6(42.9)$ & 0.399 & $10(71.4)$ & 0.906 \\
\hline \multicolumn{7}{|l|}{ Tumor size $(\mathrm{cm})$} \\
\hline$>3$ & $30(66.7)$ & & $26(57.8)$ & & $33(73.3)$ & \\
\hline$\leq 3$ & $6(50)$ & 0.288 & $4(33.3)$ & 0.132 & $7(58.3)$ & 0.086 \\
\hline \multicolumn{7}{|l|}{ Virus } \\
\hline $\mathrm{HBV}^{+}$ & $29(61.7)$ & & $25(53.2)$ & & $34(72.3)$ & \\
\hline $\mathrm{HCV}^{+}$ & $2(66.7)$ & & $1(33.3)$ & & $2(66.7)$ & \\
\hline $\mathrm{HBV}^{-} \mathrm{HCV}^{-}$ & $5(71.4)$ & 0.876 & $3(42.9)$ & 0.774 & $4(57.1)$ & 0.138 \\
\hline \multicolumn{7}{|l|}{ Differentiation } \\
\hline Well & $13(48.1)$ & & $12(44.4)$ & & $15(55.6)$ & \\
\hline Moderately & $10(62.5)$ & & $8(50)$ & & $11(68.8)$ & \\
\hline Poorly & 13 (92.9) & $0.019^{\mathrm{a}}$ & $10(71.4)$ & 0.252 & $14(100)$ & $0.012^{\mathrm{a}}$ \\
\hline \multicolumn{7}{|l|}{ PVTT } \\
\hline Positive & $20(76.90$ & & $18(69.2)$ & & $23(88.5)$ & \\
\hline Negative & $16(51.6)$ & $0.049^{\mathrm{a}}$ & $12(38.7)$ & $0.022^{\mathrm{a}}$ & $17(54.8)$ & $0.006^{\mathrm{b}}$ \\
\hline
\end{tabular}

Abbreviations: pos, positive; PVTT, portal vein tumor thrombus. ${ }^{\mathrm{a}}<0.05$; ${ }^{\mathrm{b}} \mathrm{P}<0.01$.

levels of the Hh pathway component gene transcription by RT-PCR. All of the components were expressed in HCC cell lines to different extent (Fig. 2). Expression of Shh, Ptch, Smo and Gli2 mRNAs was robustly observed in hepatoma cell lines, with predominance in SMMC-7721, but weaker expression in normal liver cell lines (L02) was noted, especially Gli2 was significantly overexpressed in SMMC7721 but almost undetectable in L02. The enhanced expression of Gli1 was only observed in Hep3B and SMMC7721. However, Ihh and Gli3 were expressed at similarly low levels in all cell lines. In addition, the different expressions of the Hh pathway components between HCC tissue and adjacent-tumor liver tissue were further confirmed. Among the 5 cell lines, Hh pathway was significantly activated in SMMC-7721, which is characterized by poor differentiation and better invasiveness. Therefore, we used it for the subsequent experiments.

Blockade of the Hh pathway reduced SMMC-7721 cell proliferation. In order to evaluate the effects of Hh pathway on cell growth, we detected proliferation of SMMC-7721 cells at interval of $12 \mathrm{~h}$ for up to $72 \mathrm{~h}$, which was incubated with KAAD-cyclopamine, a specific antagonist of $\mathrm{Hh}$ signaling. The antagonist reduced the cell proliferation in a dose- and time-dependent pattern (Fig. 3A). For each concentration, IR increased gradually over time $(\mathrm{P}<0.05)$; at

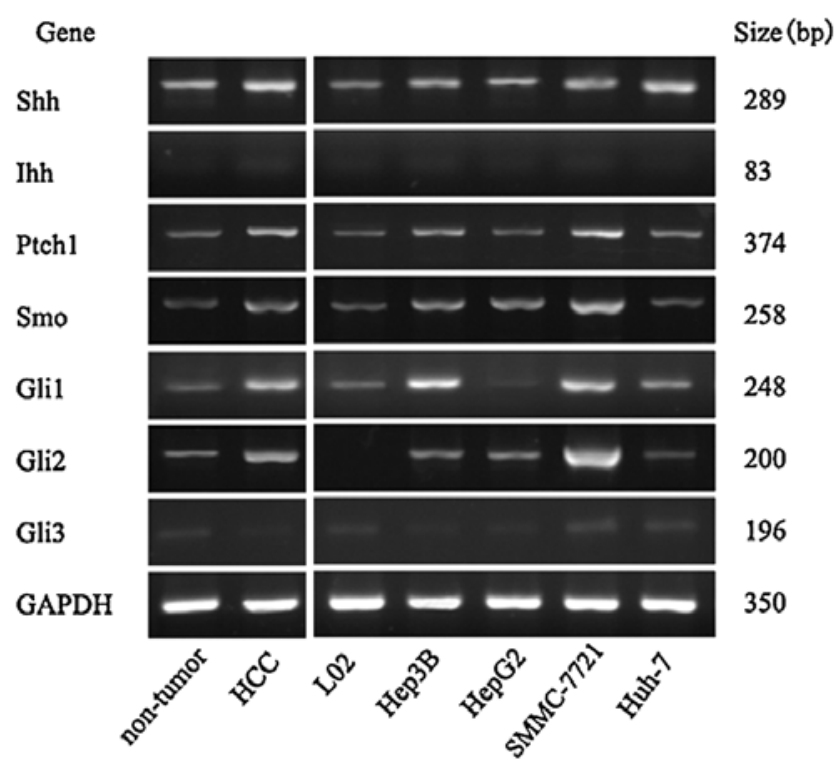

Figure 2. Expression of Hh pathway component genes in cell lines $(n=5)$ and liver tissues. RT-PCR was performed to detect the expression of Shh, Ihh, Smo, Ptch1, Gli1, Gli2, and Gli3; GAPDH level is for normalization purposes. All four hepatoma cell lines expressed these molecule mRNAs, especially in SMMC-7721. The molecules were overexpressed in HCC tissues compared with non-tumor liver tissues, which was consistent with the immunoreactivity. 
A

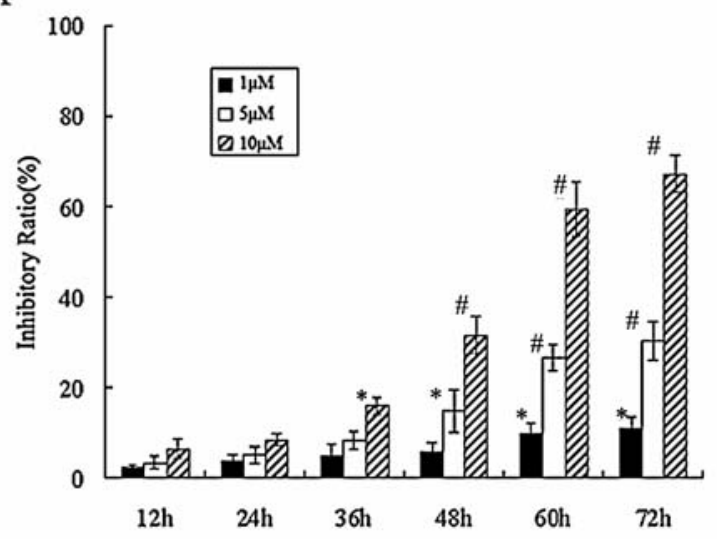

$\mathrm{C}$

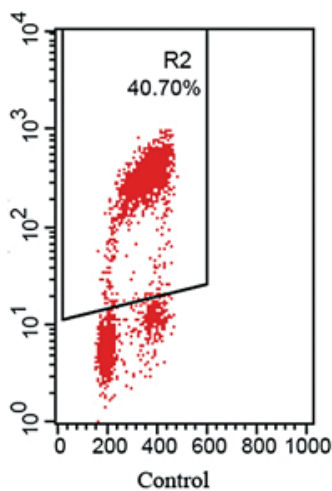

BrdU

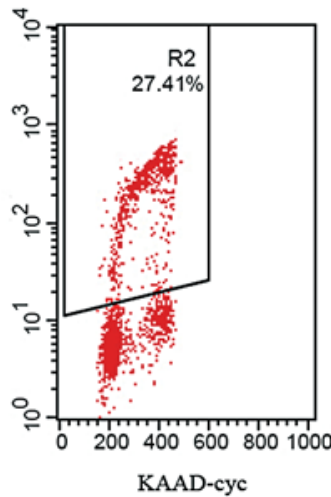

B

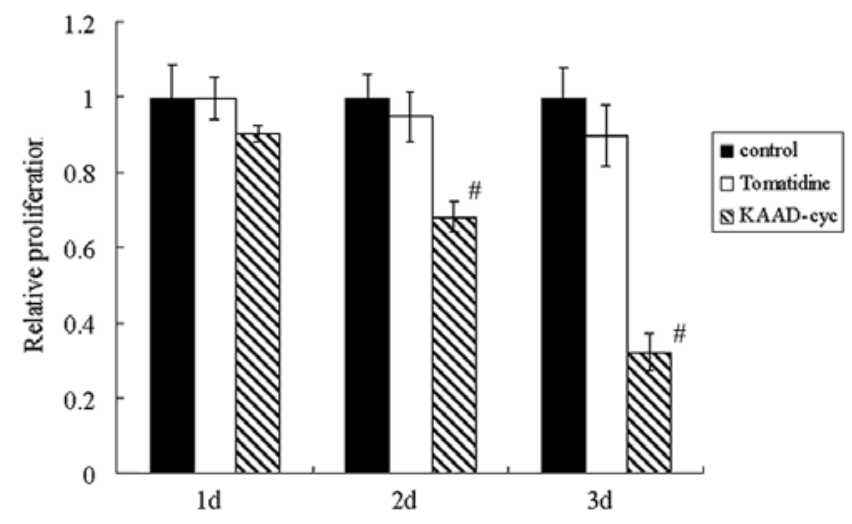

$\mathrm{D}$

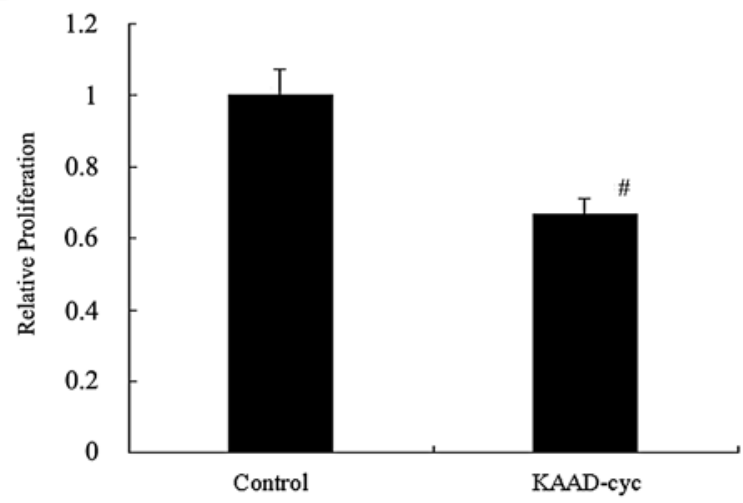

Figure 3. Blockade of the Hh pathway inhibited the growth and proliferation of SMMC-7721 cells. (A) Cells were treated with increasing dosages of KAADcyclopamine for $72 \mathrm{~h}$. Cell proliferation was determined every $12 \mathrm{~h}$ by MTT assay and represented as the relative inhibitory ratio to the untreated cells. ${ }^{*} \mathrm{P}<0.05$; ${ }^{\#} \mathrm{P}<0.01$; vs. controls. (B) The different inhibition of the same concentration of KAAD-cyclopamine and tomatidine (10 $\mu$ mol/l). Cell proliferation is indicated by the percentage of untreated controls. KAAD-cyc, KAAD-cyclopamine; ${ }^{\#} \mathrm{P}<0.01$, KAAD-cyclopamine vs. Tomatidine. (C) Representative FACS scatter diagram of SMMC-7721 after BrdU incorporation, solid line boxes mark proliferating cells. " $\mathrm{P}<0.01$. (D) Quantification of proliferating cells measured by FACS (C). The number of proliferating cells in control group was adjusted to 1 . Columns, mean of triplicate or quadruplicate samples; bars, $\mathrm{SD}$. ${ }^{\sharp} \mathrm{P}<0.01$.

each time-point, the IR rose with the increase of treatment concentration, except on the first day when no concentration treatment appeared to have a distinct inhibitory effect $(\mathrm{P}>0.05)$. The maximum IR by 1,5 and $10 \mu \mathrm{mol} / 1 \mathrm{KAAD}-$ cyclopamine treatment was $10.9 \pm 2.35 \%, 30.24 \pm 4.21 \%$, $67.34 \pm 4.18 \%$ at $72 \mathrm{~h}$, respectively. However, cell proliferation was weakly affected by the control homologue tomatidine compared with KAAD-cyclopamine ( $\mathrm{P}>0.05)$ (Fig. 3B). For validation of the role of Hh pathway in cell proliferation, we measured the DNA synthesis by more sensitive BrdU labeling assay further (Fig. 4). The result showed that KAAD-cyclopamine induced reduction of cell number in active DNA synthesis, the proportion of R2 (BrdU positive cells/total cells) was $27.41 \pm 2.2 \%$ in treated cells, remarkably less than $40.7 \pm 3.1 \%$ in controls $(\mathrm{P}<0.01)$. These findings implied that inhibition of $\mathrm{Hh}$ pathway can significantly decrease proliferation of SMMC-7721.

$K A A D$-cyclopamine induced-inhibition in invasiveness of SMMC-7721 cells. To investigate the putative role of $\mathrm{Hh}$ pathway in the invasive potential of HCC, we performed wound assays and invasion assays. As shown in Fig. 4, the motility and invasive capacity of SMMC-7721 cells were greatly suppressed by KAAD-cyclopamine. Wound assay revealed significant reductions in wound closure by $>65 \%$ for SMMC-7721 cells with blockade of the Hh pathway compared with those of control cells (Fig. 4A and B). Moreover, mean velocities of treated cells were significantly lower $(\sim 40 \%)$ than those of control cells $(24.9 \pm 3.8$ vs. $41.3 \pm 7 \mu \mathrm{m} / \mathrm{h} ; \mathrm{P}<0.01$; Fig. $4 \mathrm{C})$. Invasion assay displayed that SMMC-7721 exhibited the strongest invasive potential (71.1 \pm 11.5 cells/hpf) but to a significantly lesser extent after application of KAAD-cyclopamine $(36.1 \pm 6.4$ cells $/ \mathrm{hpf}$; $\mathrm{P}<0.01$; Fig. 4D and E). Collectively, these studies demonstrate that the Hh pathway could play some facilitatory role in invasion of $\mathrm{HCC}$.

\section{Discussion}

$\mathrm{HCC}$ is a common malignant disease with inadequate therapeutic methods, studies of the underlying molecular mechanism provide potential to identify new therapeutic target. Previous evidence has demonstrated that the $\mathrm{Hh}$ signaling plays an important role in multiple tumor types, for example, pancreatic cancer, colon carcinoma, gastric cancer, small cell lung cancer, prostate cancer, breast cancer and basal cell carcinoma (13-20). Recent studies revealed that the Hh pathway is abnormally activated in human HCC (22-24). 
A

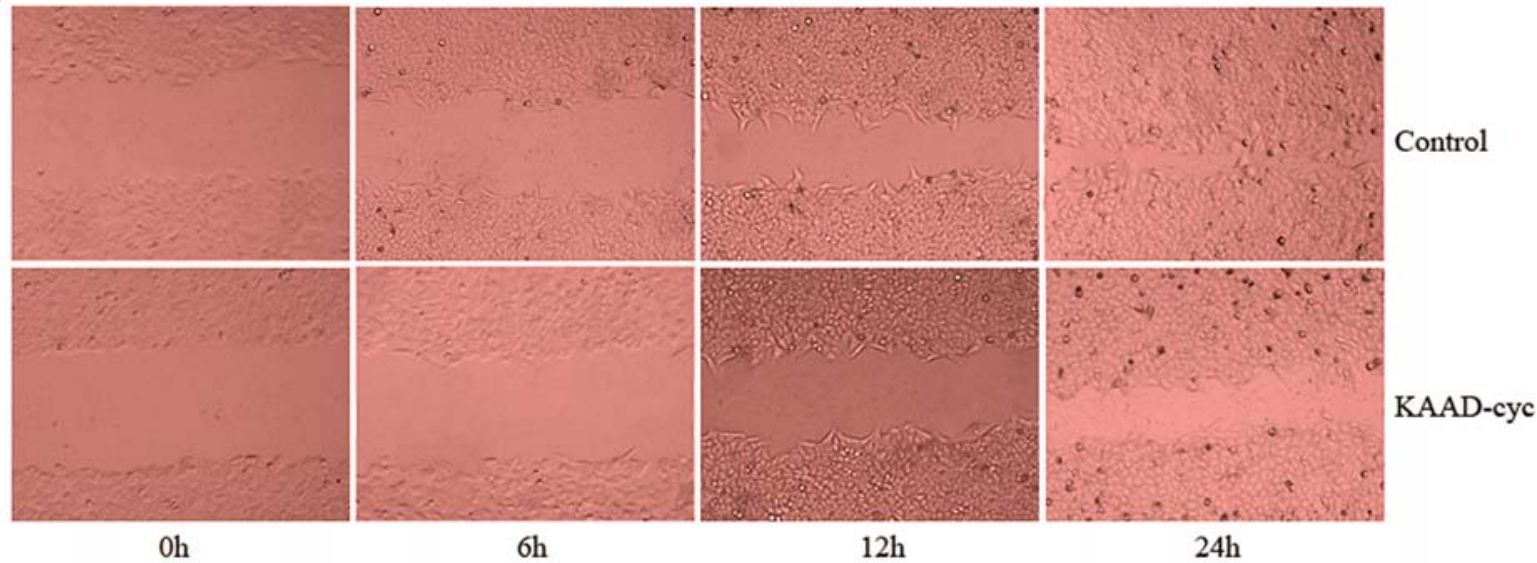

B

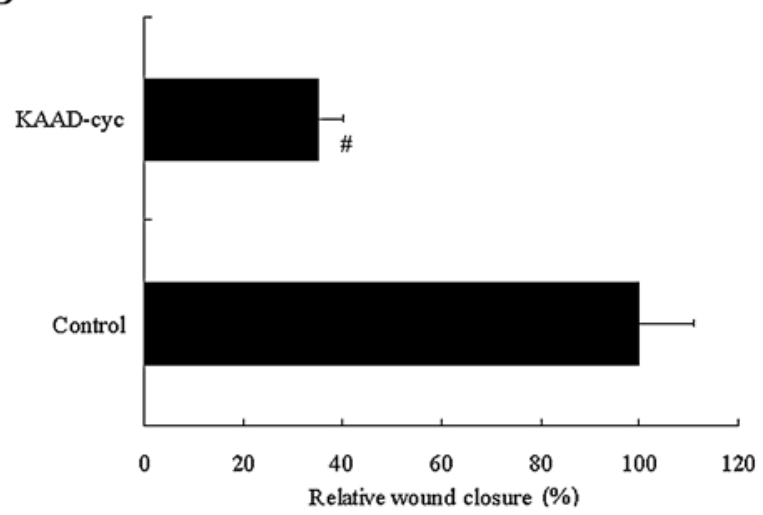

D

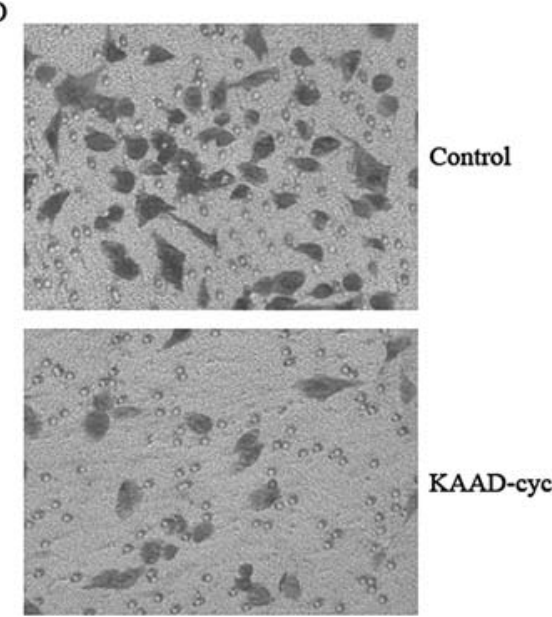

$\mathrm{C}$

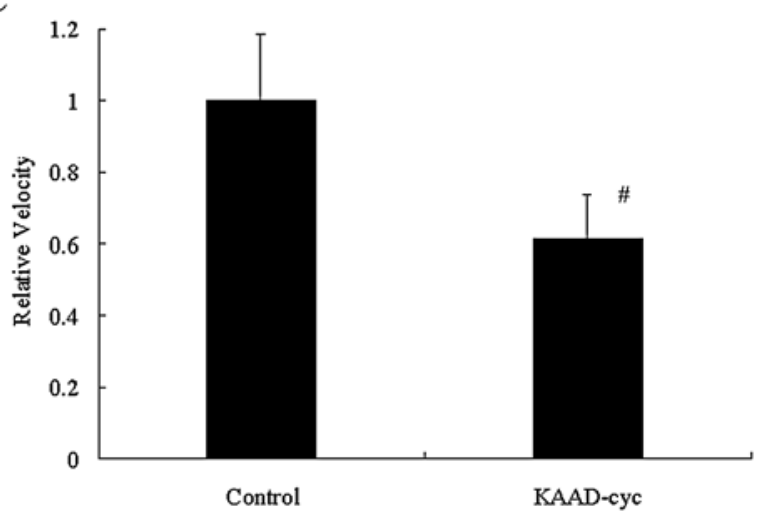

$\mathrm{E}$

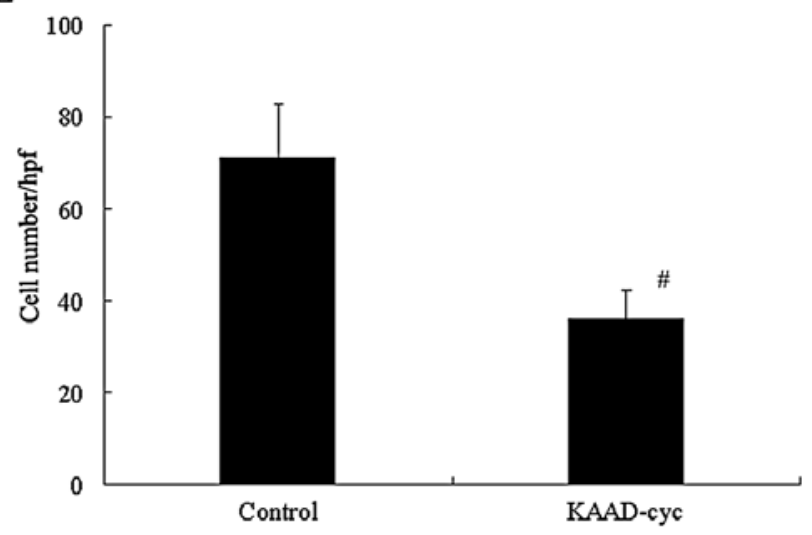

Figure 4. KAAD-cyclopamine restricted motility and invasion of SMMC-7721 cells. Cells were treated with $10 \mu$ mol/l KAAD-cyclopamine for $48 \mathrm{~h}$ then examined for invasiveness. (A) Wound closure of scrape-wounded cell monolayers over a 24-h culture period: representative photographs (x100) at $0,6,12$ and $24 \mathrm{~h}$ after wounding from 1 of 3 independent experiments are shown. (B) Percentage of wound closure corresponds to the distance between wound edges normalized to $100 \%$ wound closure for control cells. ${ }^{~} \mathrm{P}<0.01$. (C) Velocity of cells was analyzed by monitored phasecontrast of individual cells using time lapse video. Average velocities (Ave $\pm \mathrm{SD}$ ) of at least 50 cells from each of 3 independent experiments. $\mathrm{P}<0.01$. (D) Invasion across modified Boyden chambers was evaluated after $24 \mathrm{~h}$. Representative photographs of filter undersides are shown (x400). (E) Qualification of invasion cells in high-power field of (D). Data (mean \pm SD) are from 3 independent experiments each performed in triplicate. ${ }^{~} \mathrm{P}<0.01$.

However, to date no report has been presented to give a detailed description on the functional relevance of the $\mathrm{Hh}$ pathway to HCC progression.

In the present study, we found overexpression of $\mathrm{Hh}$ signaling pathway, represented by Shh, Ptch1 and Gli2, in HCC compared with corresponding adjacent-tumor liver tissues, which was in line with previous results in other cancers $(16,19)$. Moreover, the ectopic expression of Shh and Gli2 was associated with histologic differentiation of HCC, which was inconsistent with the results of Huang et al (23), who did not detect Gli2 expression and divided the differentiation degree into two groups (well-differentiated, and moderately 
to poorly-differentiated). Noticeably, we observed for the first time that Hh pathway was associated significantly with portal venous invasion of HCC. Poor differentiation and intrahepatic tumor spread through the portal vein system are the crucial histologic features of HCC aggressiveness (26). In addition, we detected the expression of Hh signaling in hepatoma cell lines and normal liver cell lines, and found a higher expression level in hepatoma cell lines especially in SMMC-7721 cells, which were regarded as poorly differentiated. These results indicated that continuous activation of the $\mathrm{Hh}$ signaling pathway is associated with histologic differentiation and invasiveness and may promote the progression of HCC.

Although it has been confirmed that the Hh pathway participates in cell migration and angiogenesis processes and is correlated with the severity of the associated tumor (2729), additionally, disruption of Hh pathway has been shown to inhibit metastasis in pancreatic cancer and gastric cancer (29-31), the relationship between the Hh signaling pathway and aggressiveness of HCC cells remains unclear. It is necessary to investigate whether the signaling influences proliferative and invasive potential of HCC cells. It has been reported that cyclopamine is a specific antagonist of the $\mathrm{Hh}$ pathway by binding to Smo and induces inactive $\mathrm{Hh}$ signaling, KAAD-cyclopamine is a synthetic cyclopaminederivative (32). We employed KAAD-cyclopamine to block the $\mathrm{Hh}$ signaling pathway in SMMD-7721 cells and to determine the effect of the pathway on proliferation and invasiveness of HCC cells. The outcomes demonstrated that KAAD-cyclopamine reduced the DNA synthesis leading to marked cell growth inhibition, moreover, the antagonist inhibited the proliferation in a dose- and time-dependent manner, the maximum inhibitory ratio close to $70 \%$. In addition to attenuation the proliferative program, the abrogation of the Hh signaling with KAAD-cyclopamine resulted in restriction in motility and invasiveness of SMMC7721 cells, the capacity of migration and invasion decreased by $\sim 40$ and $50 \%$ respectively.

It is notable that the Gli2 oncogene RNA expression level was abnormally high in HCC cell lines, significantly in SMMC-7721 cells, but it was almost undetectable in L02 cells, the normal liver cell lines. This different expression of Gli2 agrees with its different immunoreactivity between cancerous and noncancerous samples from one HCC patients. Gli2 was overexpressed in HCC with portal venous invasion or poorly differentiated samples showed positive correlation between Gli2 expression and malignant phenotype of HCC. Previous studies concentrated on the role of Gli1 oncogenes in tumorigenicity, whereas increasing evidence confirmed that Gli2 regulates Gli1 transcription and plays a critical role in the malignant phenotype of several carcinomas, including basal cell carcinoma, medulloblastomas, rhabdomyosarcomas, breast cancer and prostate cancer $(13,20,33,34)$. In some cell types, Gli2 not Gli1 is indispensable for the $\mathrm{Hh}$ signaling pathway reaction $(35,36)$. As a whole, these data indicated that Gli2 participates in the development and progression of $\mathrm{HCC}$, and future studies are needed to elucidate the underlying mechanisms.

In conclusion, our study made it clear that Hh pathway activation strongly reflects the biological aggressiveness of HCC and plays a vital role in its proliferation and invasiveness.
Blocking the Hh signaling pathway remarkably decreased HCC cell growth and motility, indicating that it could provide a new therapeutic option for HCC to improve prognosis.

\section{References}

1. Liotta LA and Kohn EC: The microenvironment of the tumourhost interface. Nature 411: 375-379, 2001.

2. Zhou J, Lei W, Shen L, Luo H and Shen ZX: Primary study of leptin and human hepatocellular carcinoma in vitro. World J Gastroenterol 18: 2900-2904, 2008.

3. Chen XP, Qiu FZ, Wu ZD, Zhang ZW, Huang ZY and Chen YF: Long-term outcome of resection of large hepatocellular carcinoma. Br J Surg 93: 600-606, 2006.

4. Yan Q, Zhang ZF, Chen XP, Gutmann DH, Xiong M, Xiao ZY and Huang ZY: Reduced T-cadherin expression and promoter methylation are associated with the development and progression of hepatocellular carcinoma. Int J Oncol 32: 1057-1063, 2008.

5. Ruiz i Altaba A, Sánchez P and Dahmane N: Gli and hedgehog in cancer: tumours, embryos and stem cells. Nat Rev Cancer 2: 361-372, 2002.

6. Ingham PW and McMahon AP: Hedgehog signaling in animal development: paradigms and principles. Genes Dev 15: 30593087, 2001

7. Cohen MM Jr: The Hedgehog signaling network. Am J Med Genet 123A: 5-28, 2003

8. Deutsch G, Jung J, Zheng M, Lora J and Zaret KS: A bipotential precursor population for pancreas and liver within the embryonic endoderm. Development 128: 871-881, 2001

9. Rubin LL and de Sauvage FJ: Targeting the Hedgehog pathway in cancer. Nat Rev Drug Discov 5: 1026-1033, 2006.

10. Elia D, Madhala D, Ardon E, Reshef R and Halevy O: Sonic hedgehog promotes proliferation and differentiation of adult muscle cells: involvement of MAPK/ERK and PI3K/Akt pathways. Biochim Biophys Acta 1773: 1438-1446, 2007

11. Palma V, Lim DA, Dahmane N, Sánchez P, Brionne TC Herzberg CD, Gitton Y, Carleton A, Alvarez-Buylla A and Ruiz i Altaba A: Sonic hedgehog controls stem cell behavior in the postnatal and adult brain. Development 132: 335-344, 2005.

12. Pasca di Magliano M and Hebrok M: Hedgehog signalling in cancer formation and maintenance. Nat Rev Cancer 3: 903-911, 2003.

13. Berman DM, Karhadkar SS, Maitra A, Montes De Oca R, Gerstenblith MR, Briggs K, Parker AR, Shimada Y, Eshleman JR, Watkins DN and Beachy PA: Widespread requirement for Hedgehog ligand stimulation in growth of digestive tract tumours. Nature 425: 846-851, 2003.

14. Thiyagarajan S, Bhatia N, Reagan-Shaw S, Cozma D, ThomasTikhonenko A, Ahmad N and Spiegelman VS: Role of GLI2 transcription factor in growth and tumorigenicity of prostate cells. Cancer Res 67: 10642-10646, 2007.

15. Velcheti V and Govindan R: Hedgehog signaling pathway and lung cancer. J Thorac Oncol 2: 7-10, 2007.

16. Katoh $\mathrm{Y}$ and Katoh M: Hedgehog signaling pathway and gastric cancer. Cancer Biol Ther 4: 1050-1054, 2005.

17. Ma X, Sheng T, Zhang Y, Zhang X, He J, Huang S, Chen K, Sultz J, Adegboyega PA, Zhang H and Xie J: Hedgehog signaling is activated in subsets of esophageal cancers. Int J Cancer 118: 139-148, 2006.

18. Mukherjee S, Frolova N, Sadlonova A, Novak Z, Steg A Page GP, Welch DR, Lobo-Ruppert SM, Ruppert JM, Johnson MR and Frost AR: Hedgehog signaling and response to cyclopamine differ in epithelial and stromal cells in benign breast and breast cancer. Cancer Biol Ther 5: 674-683, 2006.

19. Thayer SP, di Magliano MP, Heiser PW, Nielsen CM, Roberts DJ, Lauwers GY, Qi YP, Gysin S, Fernández-del Castillo C, Yajnik V, Antoniu B, McMahon M, Warshaw AL and Hebrok M: Hedgehog is an early and late mediator of pancreatic cancer tumorigenesis. Nature 425: 851-856, 2003.

20. Kump E, Ji J, Wernli M, Häusermann P and Erb P: Gli2 upregulates cFlip and renders basal cell carcinoma cells resistant to death ligand-mediated apoptosis. Oncogene 27: 3856-3864, 2008

21. Hu WG, Liu T, Xiong JX and Wang CY: Blockade of sonic hedgehog singal pathway enhanced antiproliferativer effect of EGFR inhibitor in pancreatic cancer cells. Acta Pharmacol Sin 28: $1224-1231,2007$ 
22. Sicklick JK, Li YX, Jayaraman A, Kannangai R, Qi Y, Vivekanandan P, Ludlow JW, Owzar K, Chen W, Torbenson MS and Diehl AM: Dysregulation of the Hedgehog pathway in human hepatocarcinogenesis. Carcinogenesis 27: 748-757, 2006.

23. Huang S, He J, Zhang X, Bian Y, Yang L, Xie G, Zhang K, Tang W, Stelter AA, Wang Q, Zhang H and Xie J: Activation of the hedgehog pathway in human hepatocellular carcinomas. Carcinogenesis 27: 1334-1340, 2006.

24. Kim Y, Yoon JM, Xiao X, Dean NM, Monia BP and Marcusson EG: Selective down-regulation of glioma-associated oncogene 2 inhibits the proliferation of hepatocellular carcinoma cells. Cancer Res 67: 3583-3593, 2007.

25. Yang C, Zeisberg M, Lively JC, Nyberg P, Afdhal N and Kalluri R: Integrin alphalbeta1 and alpha2beta1 are the key regulators of hepatocarcinoma cell invasion across the fibrotic matrix microenvironment. Cancer Res 63: 8312-8317, 2003.

26. Yuan RH, Jeng YM, Chen HL, Lai PL, Pan HW, Hsieh FJ, Lin CY, Lee PH and Hsu HC: Stathmin overexpression cooperates with p53 mutation and osteopontin overexpression, and is associated with tumour progression, early recurrence, and poor prognosis in hepatocellular carcinoma. J Pathol 209: 549-558, 2006.

27. Hochman E, Castiel A, Jacob-Hirsch J, Amariglio N and Izraeli S: Molecular pathways regulating pro-migratory effects of hedgehog signaling. J Biol Chem 281: 33860-33870, 2006.

28. Fu JR, Liu WL, Zhou JF, Sun HY, Xu HZ, Luo L, Zhang H and Zhou YF: Sonic hedgehog protein promotes bone marrowderived endo-thelial progenitor cell proliferation, migration and VEGF production via PI 3-kinase/Akt signaling pathways. Acta Pharmacol Sin 27: 685-693, 2006.

29. Nagai S, Nakamura M, Yanai K, Wada J, Akiyoshi T, Nakashima H, Ohuchida K, Sato N, Tanaka M and Katano M: Gli1 contributes to the invasiveness of pancreatic cancer through matrix metalloproteinase-9 activation. Cancer Sci 99: 1377-1384, 2008.
30. Karhadkar SS, Bova GS, Abdallah N, Dhara S, Gardner D, Maitra A, Isaacs JT, Berman DM and Beachy PA: Hedgehog signalling in prostate regeneration, neoplasia and metastasis. Nature 431: 707-712, 2004.

31. Yoo YA, Kang MH, Kim JS and Oh SC: Sonic hedgehog signaling promotes motility and invasiveness of gastric cancer cells through TGF- 3 -mediated activation of the ALK5-Smad 3 pathway. Carcinogenesis 29: 480-490, 2008.

32. Chen JK, Taipale J, Young KE, Maiti T and Beachy PA: Small molecule modulation of Smoothened activity. Proc Natl Acad Sci USA 99: 14071-14076, 2002.

33. Berman DM, Karhadkar SS, Hallahan AR, Pritchard JI, Eberhart CG, Watkins DN, Chen JK, Cooper MK, Taipale J, Olson JM and Beachy PA: Medulloblastoma growth inhibition by hedgehog pathway blockade. Science 297: 1559-1561, 2002.

34. Gerber AN, Wilson CW, Li YJ and Chuang PT: The hedgehog regulated oncogenes Gli1 and Gli2 block myoblast differentiation by inhibiting MyoD-mediated transcriptional activation. Oncogene 26: 1122-1136, 2007.

35. Park HL, Bai C, Platt KA, Matise MP, Beeghly A, Hui CC, Nakashima M and Joyner AL: Mouse Gli1 mutants are viable but have defects in SHH signaling in combination with a Gli2 mutation. Development 127: 1593-1605, 2000.

36. Bai CB, Auerbach W, Lee JS, Stephen D and Joyner AL: Gli2, but not Gli1, is required for initial Shh signaling and ectopic activation of the Shh pathway. Development 129: 4753-4761, 2002. 